\title{
Farmer nurseries as a catalyst for developing sustainable land use systems in southern Africa. Part B: Support systems, early impact and policy issues
}

\author{
Andreas Böhringer ${ }^{\mathrm{a}, *}$, Elias T. Ayuk ${ }^{\mathrm{b}, 1}$ \\ ${ }^{a}$ International Centre for Research in Agroforestry-Southern Africa Program, \\ PO Box 134, Zomba, Malawi \\ ${ }^{\mathrm{b}}$ International Centre for Research in Agroforestry-Southern Africa Program, c/o DRSS, \\ 5th Street Extension, Harare, Zimbabwe
}

Received 14 February 2002; received in revised form 9 October 2002; accepted 31 October 2002

\begin{abstract}
Support to farmer nurseries is classified as either "hard" referring to material inputs (tree seed, water, inoculum, tools and fencing) or "soft" (information, training and backstopping advice). Against a background of poor services for smallholder farmers in southern Africa, it was hypothesized that a number of support agents operating at the grass root level together with farmers themselves provide the different support functions needed in farmer nurseries. A study was conducted to evaluate the role of support systems in farmer nurseries in Malawi, Zambia and Tanzania. Furthermore, the early tree planting impact of farmer nurseries was assessed in Malawi. Support for hard inputs came largely from single service providers, with significant and increasing contributions coming from farmers themselves. Soft inputs came from a larger diversity of providers with collaborative effort gaining importance. There is an urgent need to facilitate grassroot level support systems with larger participation from the private sector for tree seed and from the national extension services for provision of training and backstopping advice. It was noted that individual nurseries achieved larger transplanting impact, but this did not translate into higher impact at the landscape level, because group nurseries were the predominant type. Strengthening the human capital of farmers and service providers emerged as critical in increasing impact. Farmer nurseries are shown to play a
\end{abstract}

* Corresponding author. Tel.: + 265-534289; fax: + 265-534298.

E-mail addresses: aboehringer@malawi.net (A. Böhringer), eayuk@idrc.org.sn (E.T. Ayuk).

1 Current mailing address: IDRC/SISERA, PO Box 11007, CD Annexe, Dakar, Sénégal. 
number of important and interrelated functions in building natural, human and social capital. Monitoring and evaluating farmer nurseries in catalyzing these three functions should therefore receive proper attention in assessing the impact of sustainable land use systems. Policies need to be articulated to address some of the major constraints identified.

(C) 2003 Elsevier Science Ltd. All rights reserved.

Keywords: Agroforestry; Extension services; Germplasm supply; Nurseries; Human capital; Natural capital; Social capital; Tree transplanting

\section{Introduction}

The type of support needed by smallholder farmers varies widely in southern Africa as in most of Sub-Saharan Africa. Support may be related to the technology itself, to inputs, production means, infrastructure, marketing and credit, among others. In the case of farmer nurseries, specific material inputs required are tree seed and water, and often inoculum, tools and fencing. These can be classified as 'hard' support. In addition, there is "soft" support that relates to information, training and backstopping advice.

Until recently the provision of agricultural services to smallholder farmers was still largely in the hands of the government sector in southern Africa. National agricultural extension systems have largely failed to provide the support needed by smallholder farmers. In this regard, the farmer to field staff link has been identified as the weakest one in service delivery. Furthermore, inadequate technologies, high degree of bureaucracy and poor working conditions of field staff are commonly cited as major constraints (Venkatesan and Kampen, 1998). In addition, there is lack of evidence on the contribution of public extension services to the improvement of smallholder farmer livelihoods (Haug, 1999). Overall, current support to smallholder farmers can therefore be considered marginal. As a result, the seed and fertilizer supply sectors as well as the marketing of produce have recently been liberalized as part of economic restructuring in many countries in southern Africa. These three support components are the most likely targets for privatization because they can offer profitable business opportunities, unlike in cases of smallholder farmer training and advisory services, which are likely to remain in the public domain (Venkatesan and Kampen, 1998).

The effectiveness of support systems should generally be measured in terms of what leverage they provide in achieving impact on food security, the creation of wealth and reversing the degradation of the environment. In the context of agroforestry, the extent of tree planting in the agricultural landscape expressed both as area planted to trees as well as numbers of rural households using agroforestry technologies could serve as indicators for assessing impact.

It has been shown that smallholder farmers can play a crucial role in supplying tree germplasm for the development of sustainable land use systems in three countries of southern Africa (Böhringer et al., 2003). In order to allow a better assessment of this output, it is important to understand the problems farmers face with respect to nurseries, the support systems that are needed for this achievement and, 
also the impact of tree planting on farms. Given the declining importance of national extension services in southern Africa, it was hypothesized that a number of support agents operating at the grass root level together with farmers themselves provide the different support functions needed in farmer nurseries.

The overall objective of this paper is to assess the role and functions of farmer nurseries in building natural, human and social capital for the development of sustainable land use systems. This second part focuses on farmers' problems and the role of support systems in facilitating the establishment and operation of farmer nurseries. It further assesses the impact of trees planted from farmer nurseries and discusses policy issues related to germplasm supply for smallholder farmers in the region.

\section{Materials and methods}

\subsection{The study area}

The three study areas, Shinyanga Region of Tanzania, Eastern Province of Zambia and Southern Region of Malawi were described in the first part of this paper (Böhringer et al., 2003).

\subsection{Survey methods and data analysis}

A total of 426 nurseries were sampled in the three locations over two seasons. In Malawi, the sample size was 163 nurseries in 1998/1999 and 88 in 1999/2000. In Zambia 40 nurseries were sampled in 1998/1999 and 62 and 1999/2000 seasons. In Tanzania, 73 nurseries were surveyed in the 1998/99 growing season only (Böhringer et al., submitted for publication). During field visits, interviews were conducted with farmers to collect information on problems encountered and the nature of support they received. The survey team asked open-ended questions that gave the respondents the opportunity to cite up to three major problems associated with their nursery operations. In the analysis, a cumulative weighted score (CWS) was calculated for each problem (Ayuk, 1997). Since a problem one farmer ranks as the most important may be rated as second most important by another farmer or not rated at all, a simple procedure was developed to determine the relative importance of each problem. The most important problem mentioned was assigned a value of 5 , the second the value of 3 and the third most important problem the value of 1 . The CWS was then calculated by multiplying the assigned weight by the associated number of times the problem was mentioned and then summing across the three most important problems. Thus for each problem a CWS was calculated and ranked for all the problems mentioned.

Two types of support systems were assessed. The first one related to material inputs used such as seed, water, inoculum for seedbeds, tools and fencing. The second one, which we call "soft" support, refers to inputs such as information, training and backstopping advice. For each type of support, providers were recorded. In 
principle these could be farmers, staff of development organizations, government extension staff or ICRAF staff or any combination of these providers.

A follow-up survey was carried out later in the season in Malawi to determine the extent of transplanting of seedlings from nurseries. The sample size was 145 and 111 nurseries in 1998/1999 and 1999/2000 seasons, respectively. The sample was collected randomly from the total number of 303 and 617 nurseries that had been recorded in both seasons, respectively (Table 2; Böhringer et al., 2003). The number of tree seedlings transplanted and the field area planted were assessed at the end of the growing season (March-May).

A case study to gain more insight on the impact of tree planting was also carried out in Malawi in November 2000 drawing on a sample of 37 farmers in Zomba District. This sample was derived from the total of 81 nurseries that were surveyed in Zomba District in 1998/1999 and 1999/2000. These nurseries were first stratified according to type, i.e. group or individual and then according to gender composition, i.e. those being operated by women or men. Ten nurseries were then selected at random from each of the four strata. One recipient of tree seedlings from each nursery was then randomly selected from the list of all individuals that had received seedlings, based on farmers' records at time of distribution. Accessibility of villages during the rains and availability of individuals resulted finally in interviewing a total of 37 individuals. Data were collected on gender and age of household head, number of years of household head in formal education, total number of household members and wealth rank so as to characterize the households. The wealth ranking was based on a four-tier system recognized by local communities on the basis of types of capital assets owned (land, housing, radio, bicycle, tools and livestock). Wealth ranks with original terminology used in Chichewa language given in brackets were: wealthy (opeza bwino), fairly well off (opeza bwino pangono), poor (osauka) and destitute (ovutika). Project staff used open-ended questions to address problems experienced and reasons for expanding tree planting.

Table 1

Cumulative weighted score of three major problems in 276 nurseries across three countries in southern Africa during the 1998/1999 growing season

\begin{tabular}{lcc}
\hline Problem & $\begin{array}{l}\text { Cumulative } \\
\text { weighted score }\end{array}$ & $\begin{array}{l}\text { Problem } \\
\text { rank }\end{array}$ \\
\hline None & 1351 & 1 \\
Pests on seedlings & 344 & 2 \\
Scarcity of water & 342 & 3 \\
Lack of adequate nursery space & 223 & 4 \\
Damage by livestock & 62 & 5 \\
Lack of information & 54 & 6 \\
Limited tree seed & 54 & 6 \\
High labor demand & 27 & 7 \\
Transporting seedlings & 13 & 8 \\
Lack of markets for seedlings & 5 & 9 \\
\hline
\end{tabular}


Table 2

Types of nursery support as percentage of frequencies observed according to providers in southern Africa across two seasons (1998-2000) ${ }^{\mathrm{a}}$

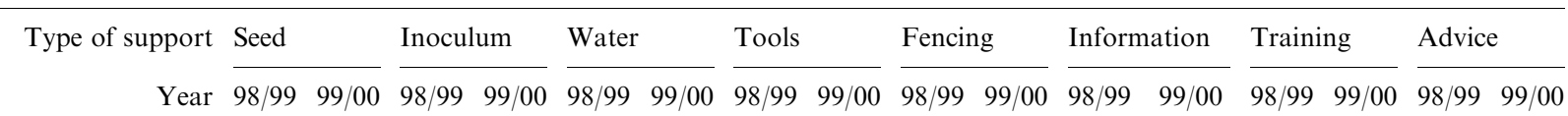

Service provider

$\begin{array}{lllllllllllllllll}\text { Year } & 98 / 99 & 99 / 00 & 98 / 99 & 99 / 00 & 98 / 99 & 99 / 00 & 98 / 99 & 99 / 00 & 98 / 99 & 99 / 00 & 98 / 99 & 99 / 00 & 98 / 99 & 99 / 00 & 98 / 99 & 99 / 00\end{array}$

None

Farmer

Extension staff

Partner staff

ICRAF

Farmer and Extension staff

Farmer and Partner staff

Farmer and ICRAF

Extension staff and Partner staff

Extension staff and ICRAF

Partner staff and ICRAF

Farmer, Extension staff and ICRAF

Farmer, Partner staff and ICRAF

Extension staff, Partner staff and ICRAF

\begin{tabular}{|c|c|c|c|c|c|c|c|c|c|c|c|c|c|c|c|}
\hline 0 & 0 & 68.7 & 80.5 & 0 & 0 & 0 & 0 & 0 & 0 & 5.1 & 2.0 & 8.4 & 1.8 & 22.9 & 17.2 \\
\hline 9.1 & 2.7 & 13.1 & 8.2 & 97.1 & 98.9 & 78.8 & 97.1 & 99.6 & 100.0 & 4.4 & 3.9 & 4.4 & 3.6 & 9.1 & 0.7 \\
\hline 1.5 & 1.1 & 0.7 & 0.5 & 0 & 0 & 0 & 0 & 0 & 0 & 3.6 & 3.0 & 3.3 & 1.9 & 1.8 & 1.6 \\
\hline 8.4 & 0.2 & 0.7 & 0.5 & 0.7 & 0.2 & 16.0 & 1.8 & 0.4 & 0 & 12.0 & 10.5 & 8.7 & 9.8 & 5.5 & 8.8 \\
\hline 65.1 & 88.4 & 14.9 & 9.3 & 0.7 & 0 & 2.9 & 0.2 & 0 & 0 & 19.0 & 19.5 & 23.3 & 44.9 & 5.1 & 4.8 \\
\hline 0 & 0 & 0.4 & 0.2 & 0 & 0 & 0 & 0 & 0 & 0 & 1.5 & 0.9 & 1.8 & 1.4 & 1.1 & 0.7 \\
\hline 0.7 & 0 & 0 & 0 & 1.5 & 0.9 & 1.8 & 0.9 & 0 & 0 & 0 & 0 & 0 & 0 & 0 & 0 \\
\hline 2.5 & 0.2 & 0 & 0 & 0 & 0 & 0.7 & 0 & 0 & 0 & 0.4 & 0.2 & 0 & 0 & 0 & 0 \\
\hline 0.7 & 0 & 0 & 0 & 0 & 0 & 0 & 0 & 0 & 0 & 0.4 & 0 & 0.4 & 0 & 0 & 0.2 \\
\hline 1.1 & 0.2 & 0 & 0 & 0 & 0 & 0 & 0 & 0 & 0 & 15.0 & 10.2 & 13.8 & 7.5 & 8.0 & 5.0 \\
\hline 9.8 & 6.6 & 1.5 & 0.9 & 0 & 0 & 0.4 & 0 & 0 & 0 & 33.9 & 49.5 & 34.9 & 29.0 & 46.2 & 61.0 \\
\hline 0.7 & 0.5 & 0 & 0 & 0 & 0 & 0 & 0 & 0 & 0 & 2.9 & 0 & 0 & 0 & 0 & 0 \\
\hline 0 & 0 & 0 & 0 & 0 & 0 & 0 & 0 & 0 & 0 & 0.4 & 0 & 0.4 & 0 & 0 & 0 \\
\hline 0.4 & 0 & 0 & 0 & 0.4 & 0 & 0.4 & 0 & 0 & 0 & 1.5 & 0.2 & 0.7 & 0.2 & 0.4 & 0 \\
\hline 275 & 441 & 275 & 441 & 275 & 441 & 275 & 441 & 275 & 441 & 274 & 440 & 275 & 441 & 275 & 441 \\
\hline
\end{tabular}

Total frequencies observed

a Covering three study areas (Malawi, Tanzania and Zambia) in 1998/1999 and two (Malawi and Zambia) in 1999/2000. 
The data from the transplanting survey in Malawi were pooled over two seasons and analyzed. The impact survey carried out in Malawi was analyzed separately. Regression analysis and independent sample tests (two-tailed $t$-tests assuming unequal variances) were carried out to determine the statistical importance of the postulated relationships.

\section{Results and discussion}

\subsection{Nursery problems}

Cumulative weighted scores (CWS) on the three most important problems experienced by farmers in operating nurseries during the 1998/1999 season are summarized in Table 1. The results show that the majority of farmers experienced no problems. It should be noted here that respondents did not perceive seed availability as an option, since ICRAF and partner organization provided starter germplasm for initiating farmer nurseries. In the absence of such incentives, availability of tree germplasm is often cited as the key constraint to farmer tree planting (Aalbaek, 2001). The most important problems in this study in descending order were pests damaging seedlings, scarcity of water and lack of adequate space for nurseries. All other problems mentioned received CWC of less than 63 (Table 1). Pests such as Mesoplatys spp. particularly attacked sesbania seedlings in the nursery, explaining the overall high rank of this problem in Zambia and Malawi where this was the major species being raised (Böhringer et al., 2003). Appropriate control methods are currently being developed (G. Sileshi, personal communication), but success will depend on adequate support being provided to farmers through training and technical advice. Ranking of the first three problems in Zambia and Malawi was the same over 2 years. Here, it is worthwhile to note that labor ranked consistently low throughout (Table 1). Overall these results on major problems encountered by farmers, show clearly that the establishment and management of nurseries was feasible for the majority of farming households, even with their limited resources and capacities.

\subsection{Support systems}

Nursery support could be grouped into two categories: hard inputs such as seeds, water, inoculum, tools, and fencing and soft inputs such as information, training and advice. The importance of different service providers expressed as percentages of frequencies observed for all types of support given to farmer nurseries over two years is summarized in Table 2. As a whole, these results show that single agents largely provided hard inputs, while soft inputs were provided by a larger number of different agents with collaborative effort among agents becoming more important (Table 2). This can probably be attributed to the fact that these soft inputs rely first of all on human capacities, which are generally scarce in the region and require large and long-term investments. 
On hard inputs, farmers themselves supplied inputs such as water, fencing and tools. There was a remarkable increase from $78.8 \%$ in $1998 / 1999$ to $97.1 \%$ in $1999 /$ 2000 for support provided by farmers themselves (Table 2). This result also demonstrates that providing these inputs to farmers would be probably counter-productive in making nursery production sustainable, yet many tree planting projects in the region still focus support on such hard inputs. Inoculum was largely not used in farmer nurseries (68.7\% not using in 1998/1999 and 80.5\% in 1999/2000). This low use of inoculum can be explained by three factors: (1) many farmers still lack knowledge about use and benefits of inoculating seed beds; (2) relative high costs for collecting inoculated soil from established stands of trees elsewhere or non-availability of such sources in some areas, and (3) the fact that mainly two species, sesbania and gliricidia, were raised in Zambia and Malawi over the years, hence the repeated use of the same nurseries reduced the need for inoculating seed beds every year. When inoculum was used, the main source of support came from ICRAF or farmers themselves. ICRAF was the main provider of seed in both years and this increasingly so $(65.1 \%$ in $1998 / 1999$ and $88.4 \%$ in $1999 / 2000)$. This result demonstrates that more investments are required in the future in establishing viable grassroot level seed supply systems in order that ICRAF's role in providing seed can be phased out as soon as possible, if farmer nurseries are to be made sustainable.

On soft support, it was noted that support from government extension services was generally minimal showing even a decrease over the 2 years (Table 2). This is remarkable because this kind of support to smallholder farmers is considered to be the core business of national extension services, which should focus on such publicgood activities that the market place is unlikely to provide (Van den Ban, 2000). In comparison, support from non-government partners was much higher in both years. Here, collaboration between ICRAF and non-government partners also gained importance in disseminating information and providing technical backstopping and advice (Table 2). This trend was, however, not observed in the case of training where ICRAF's support as a single provider increased from $23.2 \%$ in $1998 / 1999$ to $44.9 \%$ in 1999/2000. This result, taken in conjunction with ICRAF's collaboration with non-government partners, means that ICRAF was playing a dominant role in nursery training, a trend that is similar to the one discussed above with respect to support for tree seeds. There is a clear need for investing more into training of grassroot level trainers in the future in order to allow international and national research and development organizations to move into facilitating the wider process of scaling-up of agroforestry instead of providing large-scale training directly. Overall, the above results on unequal distribution of support services among providers at the grassroot level are far from a desired situation where "farmers, researchers and extensionists collaborate equally as social actors within the social practice of agricultural production" (Cornwall et al., 1993 after Haug, 1999).

Regression analysis with nursery seedling output per individual as a dependent variable (Böhringer et al., 2003) and the above listed types of support as predictors revealed significant effects in cases of support for seeds $(t$-value $=0.006)$ and for advice $(t$-value $<0.001)$. Independent sample test showed further that there was a difference $(t$-value $=0.059)$ between support provided by ICRAF and that by part- 
ners, resulting in an average output per individual of 1041 and 288 seedlings, respectively. This may also reflect differences in quality of advice given the variation in levels of human resource capacities among service providers. On a broader scale, this result also points to interdependencies between the building of human and natural capital, the latter being exemplified by nursery output (see Fig. 1; in Böhringer et al., 2003).

\subsection{Tree transplanting impact}

From the total number of 256 nurseries surveyed in Malawi across both seasons, 4718 individuals, $83.3 \%$ being women, received and transplanted a total of 1.88 million seedlings. There was no difference between years in average number of seedlings being transplanted, the overall mean being 399 seedlings per individual. This number is larger than the one reported by Aalbaek (2001) for Tanzania. The divergence is expected since farmers in Malawi primarily raised trees for soil fertility restoration, an agroforestry practice that by design requires larger number of trees per unit of land (Böhringer, 2001). Regression analysis showed that number of seedlings transplanted per individual was explained by nursery type and whether recipients of tree seedlings were group members (adjusted $R^{2}=0.344$ ). In Malawi, $94.2 \%$ of all nurseries across both years were of the group-type, producing significantly fewer seedlings for transplanting than individual nurseries (Böhringer at al., submitted for publication). Over the 2 years, the average number of seedlings was 350 and 1,201 for group and individual nurseries, respectively. Despite the larger number of trees transplanted from individual nurseries, their overall impact in terms of tree planting at the community and landscape level appeared however small, because group nurseries were the pre-dominant type in Malawi (Böhringer at al., 2003).

While nursery location showed no meaningful effect on average number of seedlings transplanted, independent sample tests revealed that home yard nurseries resulted in significantly larger numbers being transplanted (on average 1497 seedlings) compared to nurseries situated in dambo and riverbank locations. At the same time, home yard nurseries reached significantly fewer individuals, on average 8.9, while dambo and river bank nurseries reached more, on average 16.6 and 19.4 recipients, respectively ( $t$-values: 0.001 and $<0.001$, respectively). Since the majority of home yard nurseries were also of the group type, an explanation for fewer numbers of recipients being reached at transplanting could be that home yard nurseries were composed of members of the extended family and may have excluded outside recipients. A possible explanation for the increased seedling production in these home yard group nurseries, could then be that social capacities were higher allowing for more efficient nursery organization. This may further explain the restricted distribution of seedlings to a closer circle of recipients. With respect to impact, this would also point to an important effect of group composition and the relations among individual members on the diffusion and transplanting of tree seedlings. It therefore appears that group composition and relationship among members need to be analyzed in more detail in the future in order to allow a better differentiation 
among group nurseries and in explaining the varying transplanting impact they achieve.

There was a marked difference across years in the number of recipients transplanting seedlings $(t$-value $<0.001)$, with an average of 12.3 and 25.5 recipients in $1998 / 1999$ and $1999 / 2000$ seasons, respectively. Since average seedling productivity of nurseries was similar in both years, this approximate doubling in number of recipients transplanting seedlings in the second season can be interpreted as an outcome of overall investments into the scaling-up of agroforestry in the region. This may signify that increased levels of awareness created during the first season resulted in larger demand for tree seedlings among farmers in the subsequent year (Böhringer, 2001). The increased demand for tree seedlings and agroforestry was undoubtedly also aided by the negative effects of macro-economic restructuring being felt by poor Malawian households as fertilizers remained unaffordable. Notable here was again the significant difference in number of individuals receiving seedlings from individual and group nurseries, being 8.1 and 18.7 on average. It is important to keep in mind with these numbers the difference between number of individuals operating a nursery and number of individuals receiving seedlings. Differences in membership of group nurseries were already reported in the first part of this paper (see Section 3.1, Böhringer at al., 2003). While one farmer or household operated individual nurseries, there were still on average 8.1 recipients transplanting seedlings from this nursery type, because of the common social practice of sharing farm outputs with others in the community. Combining these results with number of seedlings transplanted can then be used to extrapolate to area of trees transplanted according to type of nursery. Table 3 presents estimates of areas planted to agroforestry by year and by nursery type. It shows that while in the first year the impact of both nurseries in terms of area planted was similar, in the second year, individual nurseries were again superior, resulting in planting of 4.43 ha on average compared to 1.48 ha for group nurseries (Table 3 ).

Since sustainable land use can also be seen as a function of proportion of total area planted to trees, our results clearly demonstrate that counting numbers of

Table 3

The effect of year and nursery type on number of seedlings transplanted and area planted to agroforestry in the Southern Region of Malawi over 2 years

\begin{tabular}{|c|c|c|c|c|}
\hline \multirow{2}{*}{ Nursery type } & \multicolumn{2}{|l|}{$1998 / 1999$} & \multicolumn{2}{|l|}{$1999 / 2000$} \\
\hline & Individual & Group & Individual & Group \\
\hline Average number of individuals transplanting & $4(2)^{\mathrm{a}}$ & $13(1)$ & $31(30)$ & $26(2)$ \\
\hline Average number of seedlings transplanted per individual & $1230(585)$ & $297(32)$ & $1058(862)$ & $421(33)$ \\
\hline Average number of seedlings transplanted per nursery ${ }^{\mathrm{b}}$ & 4920 & 3861 & 32,798 & 10,946 \\
\hline Average area planted to agroforestry per nursery $(\text { ha })^{\mathrm{c}}$ & 0.66 & 0.52 & 4.43 & 1.48 \\
\hline
\end{tabular}


individuals transplanting seedlings was not enough in assessing nursery impact but rather that the contribution of different nursery types in transforming land use at a community or watershed level needs also to be taken into account (Table 3). Taking here the average proportion of group nurseries (of $94.2 \%$ ) and the total of 303 and 617 nurseries recorded in both seasons (Table 3; Böhringer et al., in submission), allows an overall estimate on area planted to trees in Malawi. Across both seasons, all individual nurseries recorded lead to an estimated total area of 156.8 ha being planted to trees by farmers, while the corresponding area achieved by group nurseries was 1013.5 ha. This result was probably different in Tanzania and Zambia, because individual nurseries were of relative higher importance there (Böhringer at al., submitted for publication). Still, both nursery types enabled larger areas to be planted in Malawi in the second year. This overall increase could be attributed to gains made in skills and experience by individual farmers over time- an achievement related to growth in human capital (Fig. 1; Böhringer at al., submitted for publication). However, farmer capacities built over time cannot alone explain here the large difference observed between individual and group nurseries in the second year (Table 3). The difference in transplanting impact might reflect once more the differences in transaction costs between both types of nurseries. In support of this explanation, we observed large fluctuations in membership among groups over time (within and across seasons). This fluctuation must have affected group organization and hence nursery output, as one would anticipate considerable transaction costs incurring to groups for training new members. Since we did not study such group dynamics in more detail, this explanation remains hypothetical, but underlines that further differentiation among group nurseries would be needed in the future.

Furthermore, we also hypothesized that there might be significant interactions between group and individual nurseries in terms of different kind of capital being built (Fig. 1 in Böhringer at al., 2003), which also needs to be assessed in the future. For instance, we observed quite frequently individual nurseries evolving out of group nurseries, the latter providing crucial "human" start-up capital which later enabled individuals to become more successful in tree transplanting. Such late-benefits from group nurseries in building human capital, which triggered the formation of a number of individual nurseries, need to be evaluated in that respect. This also shows, once again, how the three development functions of building natural resource, human and social capital appear to be closely interrelated with farmer nurseries (Fig. 1; Böhringer at al., submitted for publication).

\subsection{The use of agroforestry on-farm}

The total of 37 farmers interviewed came from 16 different villages located in seven extension sections in Zomba District. Of the farmers interviewed, 31 had planted tree seedlings originating from group nurseries and six from individual nurseries. An interesting aspect here was the fact that 15 individuals out of the 31 sampled had made plans to produce seedlings on their own in the future, while the remainder declared they would continue organizing themselves in groups for raising seedlings. This result underlines the close interrelationships between group and 
individual nurseries, the former providing a training ground for individuals who operate their own nurseries later. However, there were no significant differences between group and individual nurseries in terms of the size of agroforestry plots being managed eventually by individual farmers.

Gender distribution was even among respondents as there were 14 women. The majority of farmers sampled $(64.9 \%)$ had 4 years or less of formal education $($ mean $=4.08$, standard deviation $=2.17)$. Average number of total household members was 5.78 (standard deviation $=2.40$ ). Wealth rank distribution across households sampled showed that $53 \%$ belong to the upper two wealth tiers and the remainder to the two lower ones. Among the $19 \%$ of all individuals being ranked as "destitute" there were also two village-headwomen. Overall, these results show that the use of agroforestry does not appear to be related to wealth of farmers. Hence, it is a feasible land use option also for the poor.

There were significant relationships between gender and other household characteristics on one hand and nursery impact indicators such as area planted to trees and number of trees managed by individuals on the other (Tables 4 and 5). Although the area planted was smaller for men $(0.33 \mathrm{ha})$ than for women $(0.46 \mathrm{ha})$, men managed more than three times the number of trees in their fields than women, on average 428 and 113 trees, respectively (Table 5). Multiple regression analysis of agroforestry land area managed as dependent variable on formal education $(t$-value $=0.0538)$ and nursery location $(t$-value $=0.010)$ gave an adjusted $R^{2}$-value of $0.2201 \quad(F=0.006)$. Likewise, number of trees managed could be explained in a meaningful way $\left(R^{2}=0.229, F=0.018\right)$ by age (n.s.), years in formal education $(t$-value $=0.111)$, gen$\operatorname{der}(t$-value $=0.004)$, and nursery location $(t$-value $=0.074)$.

The majority of respondents $(89.2 \%)$ planted trees in mixed systems or in a combination of mixed and relay cropping systems (Böhringer, 2001) in line with the main expected benefit of restoring soil fertility, being stated by $89.7 \%$ of farmers. Other studies (Aalbaek, 2001) have shown that soil fertility restoration was far down the reasons given by farmers in Tanzania, who due to much lower population pressure still have natural fallowing as an option for replenishing soil fertility. The

Table 4

Tree planting as affected by household characteristics among 37 smallholder farmers in Zomba District in Malawi (expressed in $P$-values from Levene's Test for Equality of Variances)

\begin{tabular}{lll}
\hline Household characteristic & $\begin{array}{l}\text { Total area } \\
\text { planted to trees }\end{array}$ & $\begin{array}{l}\text { Total number of } \\
\text { trees managed }\end{array}$ \\
\hline Tree planter is household head & 0.044 & 0.069 \\
Gender of tree planter & $0.682^{\mathrm{a}}$ & 0.012 \\
Number of years in formal education (1 year versus 5 years) & 0.008 & 0.009 \\
Wealth rank (wealthy versus fairly well off) & 0.031 & 0.055 \\
Wealth rank (wealthy versus poor) & 0.000 & 0.000 \\
Wealth rank (wealthy versus destitute) & 0.031 & 0.001 \\
Wealth rank (fairly well off versus poor) & 0.000 & $0.362^{\mathrm{a}}$ \\
Wealth rank (poor versus destitute) & 0.001 & $0.137^{\mathrm{a}}$ \\
\hline
\end{tabular}

\footnotetext{
a Non significant values, all other values significant.
} 
Table 5

Mean total area planted to trees and number of trees managed as influenced by selected household characteristics among 37 smallholder farmers in Zomba District, Malawi

\begin{tabular}{|c|c|c|c|c|}
\hline \multirow[t]{2}{*}{ Household characteristic } & \multicolumn{2}{|c|}{ Total area planted to trees (ha) } & \multicolumn{2}{|c|}{ Total number of trees managed } \\
\hline & Mean & STD & Mean & STD \\
\hline \multicolumn{5}{|c|}{ Tree planter is household head } \\
\hline Yes & 0.48 & 0.66 & 250.5 & 349.6 \\
\hline No & 0.07 & 0.04 & 71.1 & 68.5 \\
\hline \multicolumn{5}{|l|}{ Gender of tree planter } \\
\hline Man & 0.33 & 0.52 & 428.0 & 473.2 \\
\hline Woman & 0.46 & 0.67 & 112.9 & 136.4 \\
\hline \multicolumn{5}{|l|}{ Wealth rank } \\
\hline Wealthy & 0.13 & 0.14 & 55.5 & 48.4 \\
\hline Fairly well off & 0.31 & 0.33 & 452.2 & 480.6 \\
\hline Poor & 0.91 & 1.00 & 66.5 & 89.8 \\
\hline Destitute & 0.26 & 0.21 & 221.3 & 220.4 \\
\hline
\end{tabular}

results in Malawi are therefore not surprising because of the much higher population pressure forcing farmers to practice continuous cropping, the removal of fertilizer subsidies and the magnitude of those subsidies in the past. When asked about the biggest problem they faced in managing agroforestry all but two respondents settled on one major problem only. Ten problems were given in total, which could be grouped into four constraints: labor for managing agroforestry plots $(41.1 \%)$, material inputs $(23.0 \%)$, capacities $(15.4 \%)$ and slow tree performance $(15.3 \%)$. The remainder $(5.2 \%)$ of the sample gave no reply. Almost all farmers wanted to expand their tree plantings in the future $(94.6 \%)$ and mentioned restoration of soil fertility $(46.2 \%)$, substituting expensive inorganic fertilizers $(23.1 \%)$ and provision of fuel wood $(12.8 \%)$, all three goals directly linked to food security and sustainable livelihoods, as main reasons for expansion of agroforestry plots.

\subsection{Policy issues}

A major policy issue emerging from this study is the need for public investment in improving access to water in rural areas. The results of this study show that scarcity of water was the second most important problem facing farmers that wish to establish nurseries. Investments in improving water supply will not only improve human health and increase agricultural production but will also assist in expanding farmer nurseries. Developing and promoting water-harvesting practices can also assist farmers in getting prolonged access to water. Even though this water may not be safe for drinking, it could serve useful functions in other livelihood strategies. The question from an economic standpoint is who should pay for such investments. It can be argued that an increase in expansion of farmer nurseries will translate to increased tree planting that will have direct consequences on the environment. Such benefits extend beyond the farmers' fields and thereby justify public investment. 
The critical role of water in the establishment of farmer nurseries calls for ingenuity in developing appropriate strategies. In the drier areas, ${ }^{2}$ the emphasis should be on agroforestry options not requiring such a high planting effort but relying possibly on natural regeneration methods and others that require less water for tree establishment.

Another aspect that needs the attention of policy makers is that of developing a national strategy for germplasm supply. This study, in agreement with the one conducted by Aalbaek (2001), has shown that germplasm supply remains a major constraint for farmer tree planting. The various actors including government extension services, non-governmental organizations, the private sector and international and regional organizations working in this area need to develop national and regional strategies to address germplasm supply issues. Governments should limit their roles to defining an institutional and policy framework that ensures the smooth functioning of farmer oriented germplasm systems. A strategy needs to be developed, relying first and foremost on the demand-side in determining the kinds of investments that should be encouraged. Monitoring the demand side could be undertaken by non-governmental organizations, other grass-root and regional or international organizations that have direct contact with the potential beneficiaries.

Finally, there is a clear need for policies to articulate strategies for providing support in the form of training and advice. Both elements are critical for building human and social capital as the results of this study show. Governments and other institutions like ICRAF need to invest more in training of grass root trainers rather than providing large-scale training directly. ICRAF's experience shows that, under normal circumstances, each farmer trainer can train up to ten other farmers in agroforestry during one season. The spillover effect of such kind of investment into grassroot-level capacities can be huge within a short period of time (Böhringer, 2001). However, a prerequisite for such policies will be to conduct a cost-benefit analysis of the different types of farmer nurseries in the context of smallholder farmer production and livelihood strategies.

\section{Conclusions}

Results on support systems for farmer nurseries provided some insights into current service delivery at the grass root level. Support for material inputs came largely from single providers with farmers being able to support themselves for most hard inputs needed. The supply of tree seed was an exemption with ICRAF being the dominant supplier. This function carried out by an international organization, however, is only seen as a temporary one in triggering the scaling-up of agroforestry impact. There is urgent need to facilitate the establishment of community-based tree seed supply and distribution systems involving the private sector and community based organizations as much as possible in order to make tree planting sustainable in the region.

\footnotetext{
${ }^{2}$ We thank an anonymous reviewer for bringing this insight to our attention.
} 
Contribution from national extension services to all support functions studied was marginal. This was particularly severe for training and the provision of technical backstopping advice to smallholder farmers. It appears likely, however, that these two important support functions will have to remain in the public domain. So in order to make such services effective this would need increased and long-term public investments. Considerable support was given by ICRAF for grass root level training and this is where ICRAF should limit itself rather than undertaking largescale training directly. There is urgent need for national extension services to facilitate the development of grassroot level advisory services involving farmers as the main actors and, at the same time, solicit support from as many other service providers as possible. Results show that such a multi-agency and partnership approach was only emerging in case of some "soft" support functions, but needs to be extended, both in numbers of functions and number of partners collaborating, in order that much larger numbers of smallholder farmers can get the advisory services they need.

Group nurseries appeared heterogeneous, as highlighted by the case of home yard nurseries and therefore need further characterization. This will allow a better understanding of group dynamics, composition and the relationships among members, which should then be related to the cost of support services required and, ultimately, to the impact being achieved. With large numbers of women participating in nurseries and tree transplanting, their specific resource constraints need to be fully addressed. Overall results showed that farmer nurseries played a number of important and interrelated catalytic functions in building natural, human and social capital. Monitoring and evaluating farmer nurseries should therefore receive more attention in assessing the impact of sustainable land use systems.

\section{Acknowledgements}

We are grateful to the Canadian International Development Agency (CIDA) for the financial support provided to ICRAF to carry out the work reported in this paper through funding of the project "Agroforestry for Sustainable Rural Development in the Zambezi River Basin, Southern Africa Region" (R/C Project 050/ 19425, Agreement 23591). We thank the ICRAF-SA team, in particular the Country Leaders, Paramu Mafongoya (Zambia), Jumanne Maghembe (Malawi) and Robert Otsyina (Tanzania) as well as the Regional Coordinator, Freddie Kwesiga, for supporting the implementation of this study. Two students from Chancellor College at Zomba, Sarah Kaphamtengo and Kaluzi Simekinala, conducted the interviews for the impact study in Malawi. We are grateful to an anonymous reviewer for comments on an earlier draft and to Frank Place (ICRAF) for reviewing the final draft of this paper. Lastly, we like to thank our partners and farmers who have been participating in farmer nurseries in one way or another since the 1997/1998 growing season. All errors and omissions are the responsibilities of the authors. 


\section{References}

Aalbaek, A., 2001. Access to Planting Material as a Major Constraint to Farmer Tree Planting: A National Investigation of Farmer Tree Planting and Nursery Production in Tanzania. PhD dissertation, Department of Economics and Natural Resources, Royal Veterinary and Agricultural University, Denmark, 138 pages.

Ayuk, E.T., 1997. Adoption of agroforestry technology: the case of live hedges in the Central Plateau of Burkina Faso. Agricultural Systems 54, 189-206.

Böhringer, A., Ayuk, E.T., Katanga, R., Ruvuga, S., 2003. Farmer nurseries as a catalyst for developing sustainable land use systems in southern Africa, part a: nursery organization and productivity. Agricultural Systems PII: S0308-521X(02)00185-3.

Böhringer, A., 2001. Facilitating the wider use of agroforestry for development in southern Africa. Development in Practice 11 (4), 434-448.

Haug, R., 1999. Some leading issues in international agricultural extension, a literature review. The Journal of Agricultural Education and Extension 5 (4), 263-274.

Van den Ban, A. W., 2000. Different ways of financing agricultural extension. AgREN Network Paper No. 106. The Overseas Development Institute, London, UK, pp. 8-19.

Venkatesan, V., Kampen, J., 1998. Evolution of Agricultural Services in Sub-Saharan Africa: Trends and Prospects. World Bank Discussion Paper No. 39. The International Bank for Reconstruction and Development, Washington, DC, USA. 